\title{
Assessment of antimicrobial phytopeptides: lipid transfer protein and hevein-like peptide in the prospect of structure, function and allergenic effect
}

\author{
Sarfuddin Azmi ${ }^{*}$, Shahnaaz Khatoon ${ }^{2}$ and Mohd Kamil Hussain ${ }^{3^{*}} \mathbb{0}$
}

\begin{abstract}
Background: Antimicrobial peptides (AMPs) are unique natural antibiotics that are crucial effectors of innate immune systems in almost all living organisms. Several different plant antimicrobial peptides have been identified and isolated, demonstrating a high level of protection against various types of bacteria, insects, nematodes and other microbes. Along with antimicrobial function, these peptides play a wide range of crucial function in plants, such as regulation of stomata, ion channel, heavy metals and membrane fluidity.

Main body: Antimicrobial peptides show a continuum of toxicity for a variety of plants and animals pathogenic microbes and even show cytotoxicity against cancer cells. Numerous studies have shown that transgenic plants have increased the expression of AMP-encoding genes in response to biotic and abiotic stresses, and plants that express transgenic AMP genes are more responsive to biotic, abiotic and other functions. In addition to being a molecule with protective properties, various allergic reactions are associated with some phytopeptides and proteins, in particular non-specific lipid transfer protein (nsLTP) and peptide-like hevein. Pru p3 from peach is the most clinically important allergen within the nsLTP family that cause real food allergies and also triggers extreme clinical reactions. Similarly, latex-fruit syndrome was primarily associated with well-studied latex allergen Hevein (Hev b8, Hev b6) and class I chitinases.

Short conclusions: Several findings have shown that, in the near future, transgenic plants based on AMPs against the verity of pathogenic fungi, bacteria and other abiotic stresses will be released without any adverse effects. Recent study reason that association of lipid with nsLTP enhances allergic sensitization and hevein-like domain of chitinase I essentially plays a role in cross-sensitivity of latex with different fruits and nuts. This review discusses the structures and various functions of lipid transfer protein and hevein-like peptide.
\end{abstract}

Keywords: Antimicrobial peptides, Lipid transfer protein, Hevein-like peptide

*Correspondence: sazmi@psmmc.med.sa; mkhcdri@gmail.com

${ }^{1}$ Molecular Microbiology Biology Division, Scientific Research Centre (SRC), Prince Sultan Military Medical City (PSMMC), Sulaimaniyah, Riyadh

11159, Saudi Arabia

${ }^{3}$ Department of Chemistry, Govt. Raza P.G. College, Rampur, UP 244901, India

Full list of author information is available at the end of the article

\section{Background}

Antimicrobial peptides (AMPs) are host defense peptides (HDPs) found in almost all classes of life, including microorganisms, to a higher organism like plants and animals, as part of the innate immune system. These AMPs are potent, broad-spectrum antimicrobials against pathogenic bacteria, fungi, enveloped viruses and other parasites [95]. Along with antimicrobial function, these 
peptides play a wide range of crucial function in plants, like minimizing different types of abiotic stress, assisting in the reproduction process, opening and closing of stomata in process of respiration, ion channel activity, etc. $[25,48,52,83]$. Together with antimicrobial activity against plant pathogens, these peptides demonstrate toxicity to a range of microbes that display pathogenicity to animals and even some to cancer cells [36, 84].

The negative effects of chemical pesticides, the regular appearance of drug-resistant bacteria/fungi and the failure of some conventional antibiotics have all contributed to an urgent search for new antimicrobial agents or devices [75]. There have been several transgenic plants in the market, which confer extra gene of protein having great resistivity against herbicides, insect and pests. However, there are no single transgenic plants in the market, which confer resistance against pathogenic fungi and bacteria. The role of AMPs in resistance is demonstrated in numerous studies showing that transgenic plants increased AMP-encoding gene expression in response to biotic and abiotic stresses, and plants expressing transgenic AMP genes are more resistant to phytopathogens $[44,71]$. Nevertheless, recent studies on the development of transgenic plants based on antimicrobial peptides/proteins and their remarkable results suggest great promise in the near future.

There are numerous types of antimicrobial peptides reported from plant kingdom which isolated from different parts of plants, like, root, stem, leaf, flower and seeds. Purothionine from wheat flour (Triticum aestivum) was the first plant AMP reported [28]. Based on the structural motif, disulphide bridges and sequence homology, plant origin antimicrobial peptide was classified into fiveto-eight different class, viz. defensin, thionin, cyclotide; knotting-like peptide, lipid transfer protein, hevein-like peptide, snaking, MBP-1 homologue and glycine-rich peptides [32]. In the current review article, we have tried to evaluate lipid transfer protein and hevein-like peptides in the aspect of structure, function and allergic property of these peptides.

Intrinsic lipid physical affinity and the reporting of in vitro lipid transfer behaviour between membranes have been identified as lipid transfer protein $[49,50]$. Based on these characteristics, it was believed that LTPs were involved in biogenesis of membranes. However, in isolating many cDNAs and genes, the presence of a signal peptide sequence indicates that LTPs also join the secretory pathway [6]. Therefore, new roles have been proposed for plant LTPs: participation in cutin formation [37], embryogenesis [85], defense responses against phytopathogens $[57,80]$, symbiosis, and plant adaptation to different environmental conditions $[9,68]$. Low molecular mass and high thermal and proteolytic stability allow
nsLTP to reach the immune system in an intact form, and allergenicity is plausible due to it. It has recently been proposed that the association of nsLTPs with lipids enhances their allergenic properties and facilitates allergic sensitization to these proteins [35].

The hevein-like AMP family is named after the hevein isolated from the latex of the rubber tree. The main element of all hevein-like peptides is that a conservative chitin-binding site is one of their essential structural modules [45]. The chitin-binding site is not only common for hevein-like AMPs, but also other chitin-binding proteins, such as lectins, class I and IV chitinases, and some other proteins induced in wounding [4]. As like the chitin-binding domain of chitinase I and IV and UDA (Urtica dioica L.), hevein and hevein-like peptide contain six, eight or ten cysteine residues forming a typical cysteine motif, which can specifically bind to chitin, and possess antifungal activity in vitro against several chitincontaining phytopathogenic as well as non-chitin possessing fungi. As mentioned above, hevein is a peptidic constituent of natural latex. The first cases of allergic latex reactions were registered in 1927, and the frequency of occurrence dramatically increased later [7]. Interestingly, $30-50 \%$ of people with latex allergy often show allergic reactions to some plant products, especially fresh fruits like avocado, banana, kiwi fruit, nuts, etc.; this form of allergy is often referred as latex-fruit syndrome [7].

\section{Main text}

\subsection{Lipid transfer protein}

In vitro study report of lipid transfer protein of animals that assist in the transfer of phospholipids between membranes directed to uncover similar substitute in the plants. In this regard, Kader et al. in 1984 identified a basic nature protein from spinach showing the similar activity of phospholipids' transfer in in vitro condition; thereafter, study was fuelled to endeavour similar kind of protein or peptides in plants $[49,50]$. From the in vitro activity, it was hypothesized that LTPs are principal component involved in intracellular trafficking of lipids, but, after identifying the signal sequence that directs it extracellular space, the postulate was nulled [6]. There have been several studies conducted to elucidate the precise function, but no validated notion emerged till date and LTPs still remain the proteins of an undefined function of plants. Due to substantial industrial values and hostile effect over human health, LTPs have remained centre of study, such as abundance in malt which indorses taste and foaming quality in beer, and recognized as principal allergic components of several fruits [20, 52, 62, 96].

Lipid transfer protein (LTP) is usually designated as non-specific lipid transfer protein, produced by almost all land plants. Lipid transfer proteins are abundant, 
secretory, cysteine-rich with the conserved position, soluble and smaller in size with molecular weight less than $10 \mathrm{Kd}$. Class of this small size protein discovered approximately four decades before and since then continuously being added new protein. As it is produced by all land plants and their most of tissues, suggesting that this protein probably involves in life-saving process. The compact structure with the hydrophobic or non-polar tunnel was turned into a suitable candidate as lipid transfer protein between different membranous structures $[49,72,85$, 87].

Structurally, LPTs are comprised four-to-five $\alpha$-helices, which stabilized through relatively conserved four disulphide bridges with the pattern of $\mathrm{C}-\mathrm{X}_{\mathrm{n}}-\mathrm{C}-\mathrm{X}_{\mathrm{n}}-$ $\mathrm{CC}-\mathrm{X}_{\mathrm{n}}-\mathrm{CXC}-\mathrm{X}_{\mathrm{n}}-\mathrm{C}-\mathrm{X}_{\mathrm{n}}-\mathrm{C}$ (Fig. 1). In the folding of three-dimensional active form, helices create a hydrophobic tunnel, which chiefly plays an important role in lipid binding and transfers [5, 25]. LTPs are encoded by the relatively larger number of gene families in seed plant than bryophyte and pteridophytes. Based on molecular size, LTPs were classified into two groups, type1 LTP and type2 LTP, where type1 LTP is comprised of around 90 amino acids $(\sim 9 \mathrm{Kd})$ and type $2 \mathrm{LTP}$ of around $70(\sim 7 \mathrm{Kd})$ [51]. In a further study, LTPs from non-seed plants such as mosses and ferns were recognized as not belonging to one of two classes, indicating that LTPs of flowering plants were significantly modified in the course of evolution. Considering various factors like evolutionarily conserved intron, sequence similarity, the spacing between cysteine and post-translational modification, LPTs were classified into five major types, viz. LTP1, LTP2, LTPc,
LTPd and LTPg, and four minor types such as LTPe, LTPf, LTPh and LTPk [26]. In the categorization, it was observed that LTPd and LTPg are present in all the land plants from bryophytes to angiosperm, but LTPc and LTP1 are limited to vascular plants and specially LTP2 restricted to seed-bearing plants only. The presence of LTPd and LTPg in all land plants suggested that these are primitive and evolutionary conserved; however, restriction of LTP1, LTP2 and LTPc vascular and seed-bearing plants designated that these are transformed in the course of land plant evolution [26]. The naming of LTPs is quite confusing, and different research groups opted different names for the same LTPs. There is a recent review where the author put forward a method/typify of naming and urged to the scientific community to follow. In the recommended method, author suggested as xxLTPnn, where the first two letters indicated as genus and species of source and later two numbers/letters point the class and specific given number of protein/gene; for instance OsLTPd11; LTP from Oryzasativa class LTPd with gene/ protein number 11 and similarly AtLTP1.6; LTP from Arabidopsis thaliana class LTP1 with gene/protein number $6[24,46]$.

As mentioned above, LTPs are widely distributed and also abundant among all land plants, as they make up about $4 \%$ of the total soluble plant proteins. LTPs are synthesised as a precursor protein comprising with a signal domain of 21-27 amino acids that direct to the final destination [67]. The proteins of this group are highly compact, consisting of 4-5 a-helices, stabilized by four bridges of disulphide, providing robustness against
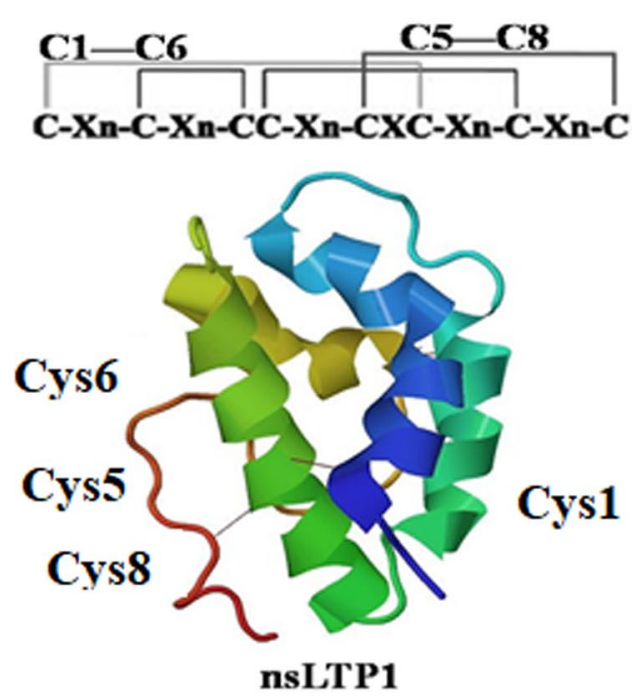
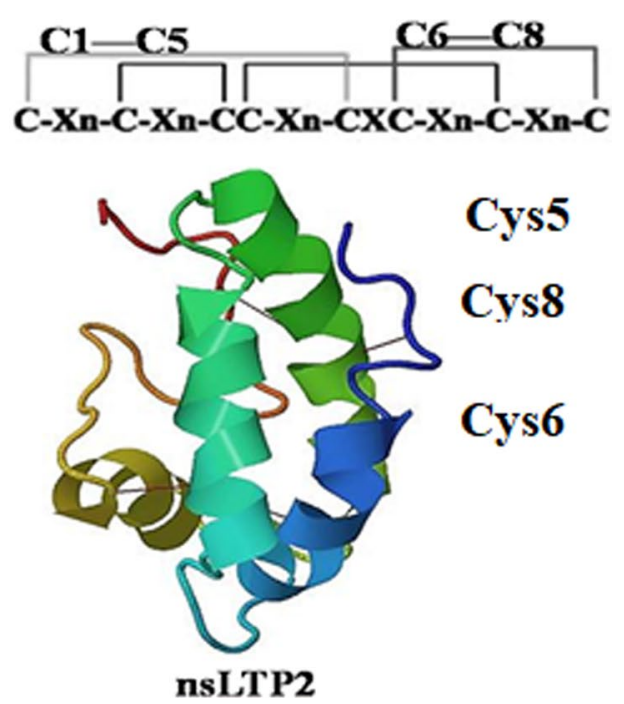

Fig. 1 Schematic representation of differential disulphides' connection pattern and tertiary structure of well structurally characterized non-specific lipid transfer protein (nsLTP) of type1 and type2. Line joining represents different positions involved in disulphide bridge formation. In type1, cyst-1 connects with cys- 6 and cys-5 with cys-8, whereas in type2, cys- 1 with cys- 5 and cys- 6 with cys-8. Tertiary model structure of nsLTP 1 and nsLTP2 
various adverse conditions. Along the axis of molecules, helices form a hydrophobic tunnel that can accommodate various types of lipids with least specificity and high flexibility $[47,86]$. Active structure of LTPs from various sources in the state of bound with lipids as well as unbound reveals that LTPs comprise with four helices connected with flexible loops and an unstructured C-terminal domain (Fig. 1) [18, 78, 86]. Helices further turned more compact with disulphide bridges and H-bonding, which provide great stability against thermal as well as enzymatic degradation. Three-dimensional structure of type 1 and type 2 is relatively more studied than other types of LTPs. The disulphide bonding pattern in type 1 is as $\mathrm{C} 1-\mathrm{C} 6$ and $\mathrm{C} 5-\mathrm{C} 8$, whereas in type $2, \mathrm{C} 1-\mathrm{C} 5$ and C6-C8 possible result differed in tertiary structure, like long tunnel hydrophobic cavity in type 1 but in type 2, LTPs comprised of two head-to-head hydrophobic cavities (Fig. 1) [15, 67]. Detail structure of other type LTPs has not been studied much except some.

Nevertheless, exact in vivo function of LTP has not been clearly understood, though various evidences suggested that LTPs play different functions along with lipid binding and transfer, such as assembly of waterproof barrier like wax and cutin $[20,52,62,96]$ over the outer surface, signalling upon ingress of biotic and abiotic stress $[25,34,48,83]$ like TaLTP40 and TaLTP75 (Tritcum aestivum) over-expresses and enhances salt tolerance upon exposer of dimethyl sulphoxide, SiLTP (S. italic) of foxtail millet exponentially increases expression upon exposer of salt $\mathrm{NaCl}, \mathrm{PEG}$, abscisic acid (ABA) and provides resistance against same and other abiotic stresses [77]. Some of LTPs also show direct microbial inhibition property as well, such as Br LTP2.1 of B. rapa found in the nectar, CcLTP2 (C. canephora) from coffee seed display antimicrobial activity against a various ranges of phytopathogen $[65,72,87]$. Some LTPs also exhibit strong antibacterial and antisepsis activity against animal/human pathogen, like McLTP (M. citrifolia) selectively inhibit grampositive bacteria and also cytokine-induced sepsis [84]. Surprisingly, the lipid transfer protein did not report anywhere to show any toxicity against either plant or animal cells. Moreover, various evidences of different studies suggested that a single function cannot be assigned solely instead of individual LTP or isoform that is likely to play specifically to multiple functions simultaneously. In addition to conventional work of lipid transfer and protective property, some LTPs also play an important role in cellwall loosening, which is likely essential in growth [74].

Lipid transfer proteins (LTPs) were present in almost all the land plants or in other words we can say that since the evolution of land plant, LTPs provide their vital role. LTPs primarily identified and characterized as a small protein with hydrophobic cavity/tunnel, which assists in the transfer of different kinds of lipids. LTPs were encoded by a high number of gene families; consequently, it is very hard to correlate phenotypic change with gene knockout or knockdown expression. However, to understand the role of LTPs, a mutation in a gene for LTP of Arabidopsis AtLTPd1 (DIR1) was directed. It was found that mutation in DIR1 gene leads to decrease in resistance against infection of $P$. syringae [23]. Similarly, knockdown of LTPG1 and LTPG2 gene in A. thaliana downregulates the production and accumulation of wax over stems [20]. Overexpression of BrLTP2 in Brassica rapa exponentially increases trichomes number over leaves and stem as well as secondary metabolite accumulation. Trichome provides the first barrier for pathogen and herbivore insect due to hairy nature, and secondary metabolites give a strong effect of fungicides, pesticide as well as provide a shield against UV [89]. StnsLTP of $S$. tuberosum response with differential expression against different abiotic stresses like heat, water deficit and salt, but transgenic potato of the same gene with overexpressing propensity also upregulates antioxidant enzymes compared to untransformed [31]. Contrastingly, overexpression of BrLTPd1 in Brassica rapa downregulates production and deposition wax over leaves [16]. Furthermore, lipid transfer protein NtLTP1.2 of tobacco was present in the liquid secretion of leaves; overexpression of this LTP increases the liquid secretion, which resultantly increases resistance to pest insects' invasion (Chen, Chen et al.). LTPs also play a crucial role in reproduction such as mutant of LTP5 gene (ltp5-1) of AtLTP1.8 (LTP A. thaliana) plant showing defect in pollination and seed formation [33], similarly on silencing of gene CaLTPc1 of Capsicum annum leading to significantly shorter pollen tube and lower the seed germination efficiency ([60]. Together, it is derived that LTPs have not any specific function, instead of one type LTP involved in multiple functions in different plants and different part of plants. It also opens window to develop plant of overexpressing certain LTPs, which would enhance secretion of wax, increase trichomes number and another physical or chemical protector that can be turned more against phytopathogen, pest/insect resistance and enhance heavy salt tolerance.

There is growing evidence suggesting that protein allergens cannot be attributed exclusively to the structural and physicochemical properties of the molecules themselves [35]. There are highly complex factors that determine the allergenicity of food proteins, including matrix effects and the association of allergens with natural ligands that influence their antigenicity and immunogenicity [88]. There are several reports revealing that lipid component or other contaminants play an important role in modulation of allergenicity of proteins [14, 
$35,88]$. For instance, an association of dietary triglycerides with peanut proteins, incubation of peanut extract and cashew allergens Ana o2 with oleic acid, binding of phosphatidylglycerol (PG) to Sin a2 (11S mustard globulin), have been reported to alter the immunogenicity of the respective allergens $[14,88]$. However, the influence of lipids' binding to food allergens on allergic sensitization and the role of lipids on their immunogenicity and allergenicity are less studied at the molecular level.

Several studies have shown that lipid transfer protein (LTP) exhibits lipid interaction heterogeneity and thus referred to as a non-specific lipid transfer protein (nsLTP) $[47,86]$. So far a limited number of studies have explored the relationship between lipids and allergenic nsLTPs and their effects on allergenic potency. Binding studies of nsLTPs with different types of lipid demonstrated different responses such as binding of certain kind of LTP with certain kind of lipid changes conformation and enhanced or reduced proteolytic stability but did not affect allergenicity; contrastingly, certain lipid binding decreases proteolytic stability but enhances allergenic property of LTP [10, 92]. For instance, binding of oleic to Pru p3 noticed that increased IgE-reactivity and basophil activation by conformational changes but in case of allergenic nsLTPs Jug r3 (English walnut) and Cor a8 (hazelnut) were relatively lesser enhancement detected $[10,79,90]$.

\subsection{Hevein-like peptide/protein}

Hevein-like peptide term was derived from the first identification of antimicrobial peptides hevein from Hevea brasiliensis [2]. Hevein primarily recognized in the lutoid of the rubber tree Hevea brasiliensis, possessed the strong antifungal activity and also identified as a major allergen, which is demonstrated as human latex-fruit syndrome. Statically, it has been observed that nearly $30-50 \%$ individual who are allergic against latex or latex-derived product also exhibit allergic reaction towards some plant products such as nut, kiwi fruit, banana, and avocado, and hence, this type allergy was referred as human latex-fruit syndrome [8, 21, 30, 33, 45]. Hevein chiefly defends fungal infection through inhibiting the growth of hyphae. Moreover, hevein-like proteins/peptides have identified from another plant also, which exhibited strong antifungal as well as antibacterial activity [30, 45]. Hevein-like proteins/peptides are approximately of 3-5 Kd with three-to-five disulphide bridge (6-10 cysteine) possessing high chitin-binding affinity [27, 30, 53]. All the peptides of this category contain a common structural motif of twenty-to-forty amino acids, encompass an abundance of glycine and conserved aromatic amino acids, which largely confer chitin-binding affinity known as a chitin-binding domain $[27,53]$, though the chitin-binding domain is not only characteristic features of hevein-like antimicrobial peptide, noted in other proteins also, such as lectins, chitin-metabolizing enzymes chitinase mainly class1 and class IV chitinase [4, 42]. Apart from the chitin-binding domain, these enzymes also possess $N$-terminal signal sequence, linker domain between chitin-binding domains and a catalytic domain. In a chitinase 1 analysis, it was found that the elimination of the chitin-binding domain reduced the metabolizing activity of chitinase but reserved antifungal activity, indicating that it does not involve antifungal activity rather for interaction [33, 42]. In any form of wound or split, the plant tries to seal by the regulated action of phytohormones such as ethylene and abscisic acid and other signalling processes. In the process of extraction of rubber, upon every puncture hevein released and interacted with glycoprotein of rubber particle and accelerated the process of aggregation of latex closing the breaks or wound to avoid access and growth of phytopathogen. Half a century ago, the sequence hevein was identified and coincidentally found to be very similar to the chitinbinding agglutinin $U$. diocica L. (UDA) of (great nettle), which an antifungal agent against chitin containing fungal strains $[11,13,59]$. Like UDA, hevein also included chitin-binding domain and exhibited antifungal activity to chitin comprising fungal strains under in vitro conditions [11]. Similar to other plant pro-antimicrobial peptides, the hevein genome has three domains, a signal domain of 17 amino acids, central active or mature, a connection of 6 amino acids linking the C-terminal domain of 144 amino acids $[3,59]$. The structural characterization through X-ray crystallography and NMR exposed that hevein comprises the characteristic motif of coil- $\beta-\beta$-coil- $\beta$, where central anti-parallel comprising $\beta$-sheet surrounded through coiled and stabilized with disulphide bridges (Fig. 2). Chitin and hevein interaction studies using NMR, ITC and molecular simulation recognized that Ser19, Trp21, Trp23, Tyr30 and amino acids between thirteen and sixteen were primarily involved in the interaction. In one interaction analysis with oligosaccharides (chitins), it was investigated that replacement of Ser19 (polar residues) with Asp (polar acidic nature) significantly decreased binding affinity to oligosaccharides $[3,17,69]$.

Hevein-like peptide is usually classified into three groups based on the contents of the cysteine residues (number of disulphide bridges), which are $8 \mathrm{C}, 6 \mathrm{C}$ and $10 \mathrm{C}$, respectively. Many of these disulphide bridges come to the $N$-terminal, such as Cys1-CysIV, CysII-CysV, CysIII-CysVI, and fourth disulphide CysVII-CysVIII towards C-terminal (Fig. 2a). In Class 6C, the same as $8 \mathrm{C}$ contains three $\mathrm{N}$-terminus disulphide bridges and the fourth C-terminal disulphide link is truncated. (Fig. 2a). However, in $10 \mathrm{C}$, an addition disulphide exists towards 


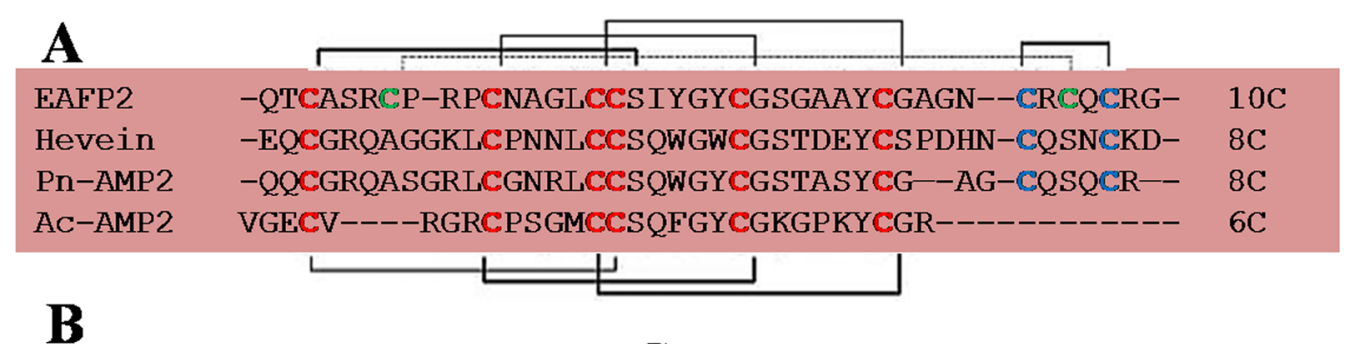

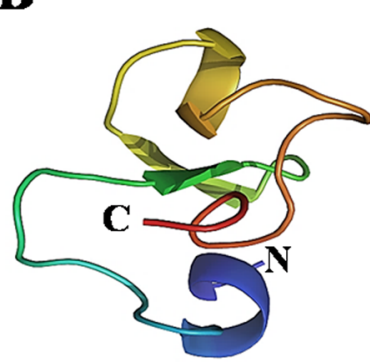

\section{C: Hevein Like eg; EPFP2}

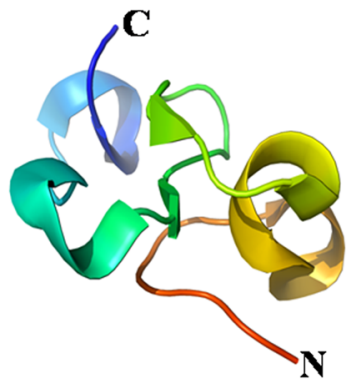

\section{C: Hevein eg; Hevein}

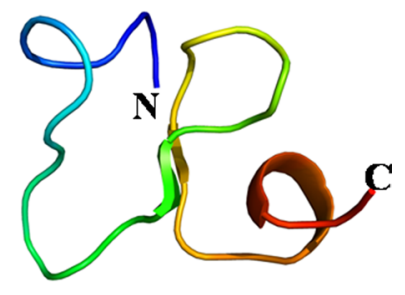

\section{C: Hevein like eg; Ac-AMP2}

Fig. 2 Overlapping sequence and tertiary structure of the different types of hevein or hevein-like protein/peptides (a). An overlapping sequence of different hevein and hevein-like peptides/proteins; bold grey $\mathrm{C}$ in the sequence represents conserved cys position throughout different groups, viz. $10 \mathrm{C}, 8 \mathrm{C}$, and $6 \mathrm{C}$ of hevein-like peptide and different family plants, grey C represents additional cys of group $8 \mathrm{C}$, which involve in disulphide bridge of $\mathrm{C}$-terminus, light grey $\mathrm{C}$ represents furthermore additional cys of $10 \mathrm{C}$ which connect $\mathrm{N}$-to $\mathrm{C}$ terminus through disulphide bond and -dash line placed to denotes variability in length in the process of alignment of sequence (b). The tertiary structure of each representative group of hevein-like peptides

$\mathrm{C}$-terminal or connecting $\mathrm{C}$-terminus to $\mathrm{N}$-terminus (Fig. 2a) [3, 38, 69, 70]. The 6C hevein-like peptides contain short C-terminal domain of 25-30 amino acids without protein cargo property. However, $8 \mathrm{C}$ hevein-like peptides contain variable kinds of $\mathrm{C}$-terminal domain. Except for mortified, which encodes a bioactive protein, most angiosperm-derived $8 \mathrm{Cs}$ have a long C-terminal domain. But gymnosperm identified $8 \mathrm{C}$ containing shorter C-terminal domain and free from protein cargo $[1,39,56]$.

Hevein and several other hevein-like peptides belong in class 8C, such as Pn-AMP1 and Pn-AMP2, (P. nil morning glory), Fa-AMP1 and Fa-AMP2 (F. esculentum Buckwheat), $\mathrm{mO} 1$ and $\mathrm{mO} 2$ (M. oleifera drumstick), Avin A (A. sativa L Oat), ginkgolide (Gymnosperm) set of eleven peptides, etc. [29] [54, 61, 63, 93]. Pn-AMP1 and PnAMP2 are very basic (i.e. PI is more than 12) and very stable against temperature. These hevein-like peptides exhibit very potent antifungal activity against chitin and non-chitin fungal strains, mainly through depolarization of hyphae membrane. Also it is identified as the first peptide of this class used for the production of a transgenic plant; Pn-AMP transgenic tomato and tobacco showed high resistance to various pathogenic fungal strains ([12, 29, 55]. Fa-AMP1 and Fa-AMP2, along with antifungal, also show potent antibacterial activity in the range of
$11-36 \mu \mathrm{g} / \mathrm{mL}$. This set of peptide contains approximately $50 \%$ cysteine and glycine of total amino acids content [63]. Similarly, Avisin A, first chitin-binding peptide identified from cereal grains, comprises 10 glycines and 8 cysteines in the total of 37 amino acids long peptides. Recently, in this class $\mathrm{mO} 1$ and $\mathrm{mO} 2$ identified from the leaves of drumstick comprise 44 amino acids, mainly asparagine and glutamine [61].

Class-6C hevein-like peptides is a comparatively shorter chitin-binding domain composed of antifungal peptide. It appears that the Class- $6 \mathrm{C}$ peptides are a truncated form of $8 \mathrm{C}$ hevein, with 10 amino acids separated from the $\mathrm{C}$-terminus. Most of the peptides of this class were recognized from Amaranthaceae family. Very first peptide Ac-AMP1 and Ac-AMP2 of this class were extracted from the seeds of A. caudatus L. Both AcAMP1 and Ac-AMP2 are similar in sequence except Ac-AMP2 containing an extra amino acid arginine at $\mathrm{C}$-terminus. It is relatively mildly anti-fungal and selectively antibacterial to Gram-positive strains [81]. There are several class-6C peptides isolated from different species of the Amaranthaceae family, containing similar sequences of Ac-AMPs, such as Ay-AMP (A. hypochondriacus) similar to Ac-AMP2 [66], Ar-AMP (A retroflexus) similar to Ac-AMPs, except for three places where similar nature of amino acids has been substituted [53] 
and ASG1(A. sessilis L.) similar to Ac-AMP1 with few substitutions [73]. IWF4 isolated from areal part of $B$. vulgaris L. of Amaranthaceae family and approximately 66\% homologous of Ac-AMP sequence, exhibit relatively more affinity for chitin compare to chitinase enzyme and inhibit even germination of spore of C. beticola ([41]. SmAMP3 and homologs were identified from areal part of chickweed and seeds, comprised of 35 amino acids, and demonstrated exclusively antifungal activity against several pathogenic fungal strains. These peptides contain an extra hevein-like domain apart from $N$-terminus signal sequence, mature peptide and $\mathrm{C}$-terminal domain, which attached with active peptide through linker sequence ([41]. Furthermore, GAFP, a 38 amino acid long peptide of $6 \mathrm{C}$ with a large array of anti-fungal activities isolated from G. biloba (medicinal plant), demonstrates a very different primary structure compared to Ac-AMPP ([40].

In comparison with $8 \mathrm{C}$, hevein-like peptides of $10 \mathrm{C}$ comprise extra disulphide bridges towards $\mathrm{C}$-terminus or connecting $\mathrm{C}$-terminus to $\mathrm{N}$-terminus. In class $10 \mathrm{C}$, EAFP1 and EAFP2 were first peptides isolated from the bark of the olive (E. ulmoides). These are made up of 41 amino acids and one of them differed from the other at position 27, where Asn replaces Ala. $\mathrm{N}$-terminal glutamic acids of these peptides are modified to form pyro-glutamic acids. EAFP peptides demonstrate wide-spectrum inhibitory activity against chitin-containing and chitinfree fungi [56]. Structural characterization of X-ray and NMR revealed that EAFPs are globular and more compact compared to other hevein-like peptide with the pattern of $3_{10}$ helix- $\beta-\beta$ - $\alpha$-helix- $\beta$ (Fig. 2 ). In these, the fifth disulphide bridge connects the $N$-terminus region to the $\mathrm{C}$-terminus, and the presence of many basic residues, mainly Arg, transforms into positively charged compact globular molecules [76, 94]. Another peptide of this class is wheat antimicrobial peptide (WAMPs) isolated recently from seeds of a highly resistant variety of wheat $T$. kiharae D. In contrast to EAFPs, fifth disulphide bridge of WAMP-1a connects C-terminus region to central region instead of $\mathrm{N}$-terminus part of the peptide [22]. WAPM is quite similar to chitin-binding domain Chitinase I with substitution of Ser with Gly at the 20th position and additional Ser at the 36th position. Possibly due to these differences, WAMPs exhibit lower binding constant compared to chitinase and display inhibitory activity against $\mathrm{Zn}$-metalloprotease (fungalysin) which is normally released from the fungus to metabolize chitinase [22], Van den [91]. Ee-CPB peptide 10C, isolated from the leaves and bark of the spindle tree E. europaeus, shows strong antifungal activity. Unlike the above-mentioned $10 \mathrm{C}$ hevein-like peptides, the fifth disulphide bridge of the Ee-CPB is confined to the C-terminus portion [43]. Ee-chitinase or Chitinase1 and Ee-CPB isolated from the spindle tree are extremely similar in sequence, but there are four disulphide bridges in Ee-chitinase. Compared to other hevein-like peptides, the Ee$\mathrm{CPB}$ contains the longest $\mathrm{C}$-terminal domain similar to chitinase I or chitinase IV [43].

Hevein-like peptides have also been tested for transgenic effectiveness and efficiency similar to defensins and other phytopeptides. The first transgenic of hevein-like peptides was developed in mustard (Brassica juncea) to demonstrate resistance against fungus, A. brassicae [55, 61]. Thereafter, several transgenics of hevein-like peptides were made, like, Pn-AMP2 in tobacco and tomato, showing significant resistance against late blight causing P. parasitica [19]; similarly, Pn-AMP2 in tomato successfully showed greater resistance towards fungi $P$. capsici and $F$. oxysporum [64]. Contrastingly, the transgenic of 6C hevein-like peptide Ac-AMP2 in tobacco and tomato did not show any enhancement of resistance against fungi, $B$. cinerea and A. longipes; however, the isolated peptides from the same transgenic exhibited in vitro antifungal activity towards the same [82]. However, transgenic of other $6 \mathrm{C}$ hevein-like peptide SmAMP1 and SmAMP2 in tobacco showed excellent enhancement in resistant towards plant pathogenic fungi T. basicola and B. sorokiniana. To demonstrate resistance to a wider range of microbes, a combination of multiple antimicrobial peptide genes could be used to develop robust transgenic $[19,64,82]$.

Based on the clinical finding of an unusually high incidence of fruit hypersensitivity in latex allergic patients, 'latex-fruit syndrome' was proposed [7, 58]. The key fruits included in the study were chestnut, avocados and bananas, but kiwi, papaya and other foods were also comprised. Nearly $30-50 \%$ of latex allergic patients of the different study displayed hypersensitivity one or more of the fruits and approximately half of the episodes recorded were systematic anaphylactic reactions, highlighting their significance [58]. Enzyme chitinases are found in most plants as protective molecules. Mainly, chitinases I and IV contain hevein-like domain at $\mathrm{N}$-terminal, findings of various studies of immunoblot inhibition and crossreactivity with condensed components of chitinases, indicating that allergic to latex is most likely to have cross-sensitization with other foods (i.e. avocado, kiwi, chestnut, banana) [58].

\subsection{Transgenic development and future perspectives}

Due to the large number of gene families that encode LTPs, it is difficult to correlate phenotypic changes with gene knockout or knockdown expression. However, several studies have attempted to show that mutation, upregulation, or transgenic of specific genes had a significant impact on resistance to certain infections, 
accumulation of anti-oxidant enzymes, or some phenotypic effect, for instance mutation in gene of Arabidopsis AtLTPd1 (DIR1) lead to decrease in resistance against infection of $P$. syringae, knockdown of LTPG1 and LTPG2 gene in A. thaliana downregulates the production and accumulation of wax over stems, StnsLTP of $S$. tuberosum, transgenic potato of same gene with overexpressing propensity also upregulates antioxidant enzymes compared to untransformed, etc. Similarly, several transgenic studies of hevein-like peptides have been conducted in order to better understand the development of resistance against pathogenic fungi. The first transgenic of hevein-like peptides was made in mustard (B. juncea), and thereafter, several transgenics of hevein-like peptides were made like Pn-AMP2 in tobacco and tomato, Pn-AMP2 in tomato, SmAMP1 and SmAMP2 in tobacco showed excellent enhancement in resistant towards plant pathogenic fungi, etc. These transgenicity studies could potentially pave the way for the development of peptide-based transgenics against pathogenic fungi and other adverse biotic and abiotic stressors.

\section{Conclusions}

Antimicrobial peptides are very primitive, essential and indispensable protection molecules of nearly all biological systems, among different innate defense methods. The majority of plant antimicrobial peptides, relative to the animal system, contain several disulphide bridges that provide compactness and stability to the adverse environments and even to the metabolic enzymes. As previously discussed, many transgenic plants have been studied with different antimicrobial peptides and different levels of resistance to phytopathogenic fungi have been observed. Success report states that in the foreseeable future, transgenic plants based on AMPs against pathogenic fungi and bacteria will be released without any adverse effects. Hevein-like peptides have also been tested for transgenic effectiveness and efficiency similar to defensins and other phytopeptides. Lipid transfer proteins (LTP) present almost all the land plants or in other words we can say that since the evolution of land plant LTPs provide their vital role. In addition to being protective molecules, a variety of allergic reactions are associated with certain phytopeptides and proteins, in particular nsLTP and hevein-like peptide.

\section{Abbreviations}

AMPs: Antimicrobial peptides; nsLTP: Non-specific lipid transfer protein; LTPS: Lipid transfer proteins; HDPs: Host defense peptides; PG: Phosphatidylglycerol; NMR: Nuclear magnetic resonance.

\section{Acknowledgements}

We acknowledge the Scientific Research Center, Prince Sultan Military Medical City for all financial supports.

\section{Authors' contributions}

(1) SA and MKH done writing draft, reviewed and edited the article; (2) SK reviewed and edited the article. We confirm that the manuscript has been read and approved for submission by all the authors.

\section{Funding}

Not applicable.

Availability of data and material

Not applicable.

\section{Declarations}

Ethics approval and consent to participate

Not applicable.

\section{Consent for publication}

Not applicable.

\section{Competing interests}

The authors declare that they have no competing interests.

\section{Human and animal rights}

The manuscript does not report on or involve the use of any animal or human data or tissue.

\section{Author details}

${ }^{1}$ Molecular Microbiology Biology Division, Scientific Research Centre (SRC), Prince Sultan Military Medical City (PSMMC), Sulaimaniyah, Riyadh 11159,

Saudi Arabia. ${ }^{2}$ Department of Botany, DN College, Meerut, UP 250002, India.

${ }^{3}$ Department of Chemistry, Govt. Raza P.G. College, Rampur, UP 244901, India.

Received: 31 December 2020 Accepted: 11 October 2021

Published online: 26 October 2021

\section{References}

1. Aboitiz N, Vila-Perelló M, Groves P, Asensio JL, Andreu D, Cañada FJ, Jimenez-Barbero J (2004) NMR and modeling studies of protein-carbohydrate interactions: synthesis, three-dimensional structure, and recognition properties of a minimum hevein domain with binding affinity for chitooligosaccharides. Chem BioChem 5(9):1245-1255

2. Archer B (1960) The proteins of Hevea brasiliensis latex. 4. Isolation and characterization of crystalline hevein. Biochem J 75(2):236-240

3. Asensio JL, Cañada FJ, Siebert H-C, Laynez J, Poveda A, Nieto PM et al (2000) Structural basis for chitin recognition by defense proteins: GlcNAc residues are bound in a multivalent fashion by extended binding sites in hevein domains. Chem Biol 7(7):529-543

4. Beintema JJ (1994) Structural features of plant chitinases and chitinbinding proteins. FEBS Lett 350(2-3):159-163

5. Berecz B, Mills EN, Tamas L, Lang F, Shewry PR, Mackie AR (2010) Structural stability and surface activity of sunflower $2 \mathrm{~S}$ albumins and nonspecific lipid transfer protein. J Agric Food Chem 58(10):6490-6497. https://doi. org/10.1021/jf100554d

6. Bernhard WR, Thoma S, Botella J, Somerville CR (1991) Isolation of a CDNA clone for spinach lipid transfer protein and evidence that the protein is synthesized by the secretory pathway. Plant Physiol 95(1):164-170. https://doi.org/10.1104/pp.95.1.164

7. Blanco C, Carrillo T, Castillo R, Quiralte J, Cuevas M (1994) Latex allergy: clinical features and cross-reactivity with fruits. Ann Allergy 73(4):309-314

8. Blanco C, Diaz-Perales A, Collada C, Sánchez-Monge R, Aragoncillo C, Castillo R et al (1999) Class I chitinases as potential panallergens involved in the latex-fruit syndrome. J Allergy Clin Immunol 103(3):507-513

9. Blein JP, Coutos-Thevenot P, Marion D, Ponchet M (2002) From elicitins to lipid-transfer proteins: a new insight in cell signalling involved in plant 
defence mechanisms. Trends Plant Sci 7(7):293-296. https://doi.org/10. 1016/s1360-1385(02)02284-7

10. Bogdanov IV, Shenkarev ZO, Finkina El, Melnikova DN, Rumynskiy El, Arseniev AS, Ovchinnikova TV (2016) A novel lipid transfer protein from the pea Pisum sativum: isolation, recombinant expression, solution structure, antifungal activity, lipid binding, and allergenic properties. BMC Plant Biol 16(1):107

11. Broekaert I, Lee H-I, Kush A, Chua N-H, Raikhel N (1990) Wound-induced accumulation of mRNA containing a hevein sequence in laticifers of rubber tree (Hevea brasiliensis). Proc Natl Acad Sci 87(19):7633-7637

12. Broekaert WF, Marien W, Terras FR, De Bolle MF, Proost P, Van Damme J et al (1992) Antimicrobial peptides from Amaranthus caudatus seeds with sequence homology to the cysteine/glycine-rich domain of chitin-binding proteins. Biochemistry 31(17):4308-4314

13. Broekaert WF, Van Parijs J, Leyns F, Joos H, Peumans WJ (1989) A chitinbinding lectin from stinging nettle rhizomes with antifungal properties. Science 245(4922):1100-1102

14. Bublin M, Eiwegger T, Breiteneder $H$ (2014) Do lipids influence the allergic sensitization process? J Allergy Clin Immunol 134(3):521-529

15. Carvalho Ade O, Gomes VM (2007) Role of plant lipid transfer proteins in plant cell physiology-a concise review. Peptides 28(5):1144-1153. https:// doi.org/10.1016/j.peptides.2007.03.004

16. Chae K, Kieslich CA, Morikis D, Kim S-C, Lord EM (2009) A gain-of-function mutation of Arabidopsis lipid transfer protein 5 disturbs pollen tube tip growth and fertilization. Plant Cell 21 (12):3902-3914

17. Chávez MI, Vila-Perelló M, Cañada FJ, Andreu D, Jiménez-Barbero J (2010) Effect of a serine-to-aspartate replacement on the recognition of chitin oligosaccharides by truncated hevein. A 3D view by using NMR. Carbohydr Res 345(10):1461-1468

18. Da Silva P, Landon C, Industri B, Marais A, Marion D, Ponchet M, Vovelle F (2005) Solution structure of a tobacco lipid transfer protein exhibiting new biophysical and biological features. Proteins 59(2):356-367. https:// doi.org/10.1002/prot.20405

19. De Bolle MF, Osborn RW, Goderis IJ, Noe L, Acland D, Hart CA et al (1996) Antimicrobial peptides from Mirabilis jalapa and Amaranthus caudatus: expression, processing, localization and biological activity in transgenic tobacco. Plant Mol Biol 31(5):993-1008

20. Debono A, Yeats TH, Rose JK, Bird D, Jetter R, Kunst L, Samuels L (2009) Arabidopsis LTPG is a glycosylphosphatidylinositol-anchored lipid transfer protein required for export of lipids to the plant surface. Plant Cell 21(4):1230-1238. https://doi.org/10.1105/tpc.108.064451

21. Diaz-Perales A, Collada C, Blanco C, Sanchez-Monge R, Carrillo T, Aragoncillo C, Salcedo G (1999) Cross-reactions in the latex-fruit syndrome: a relevant role of chitinases but not of complex asparagine-linked glycans. J Allergy Clin Immunol 104(3):681-687

22. Dubovskii PV, Vassilevski AA, Slavokhotova AA, Odintsova TI, Grishin EV, Egorov TA, Arseniev AS (2011) Solution structure of a defense peptide from wheat with a 10-cysteine motif. Biochem Biophys Res Commun 411(1):14-18

23. Duwadi D, Shrestha A, Yilma B, Kozlovski I, Sa-Eed M, Dahal N, Jukosky J (2018) Identification and screening of potent antimicrobial peptides in arthropod genomes. Peptides 103:26-30

24. Edstam MM, Blomqvist K, Eklof A, Wennergren U, Edqvist J (2013) Coexpression patterns indicate that GPI-anchored non-specific lipid transfer proteins are involved in accumulation of cuticular wax, suberin and sporopollenin. Plant Mol Biol 83(6):625-649. https://doi.org/10.1007/ s11103-013-0113-5

25. Edstam MM, Laurila M, Hoglund A, Raman A, Dahlstrom KM, Salminen TA et al (2014) Characterization of the GPl-anchored lipid transfer proteins in the moss Physcomitrella patens. Plant Physiol Biochem 75:55-69. https:// doi.org/10.1016/j.plaphy.2013.12.001

26. Edstam MM, Viitanen L, Salminen TA, Edqvist J (2011) Evolutionary history of the non-specific lipid transfer proteins. Mol Plant 4(6):947-964. https:// doi.org/10.1093/mp/ssr019

27. Egorov T, Odintsova T (2012) Defense peptides of plant immune system. Bioorg Khim 38(1):7

28. Fernandez de Caleya R, Gonzalez-Pascual B, Garcia-Olmedo F, Carbonero P (1972) Susceptibility of phytopathogenic bacteria to wheat purothionins in vitro. Appl Microbiol 23(5):998-1000

29. Fujimura M, Minami Y, Watanabe K, Tadera K (2003) Purification, characterization, and sequencing of a novel type of antimicrobial peptides,
Fa-AMP1 and Fa-AMP2, from seeds of buckwheat (Fagopyrum esculentum Moench.). Biosci Biotechnol Biochem 67(8):1636-1642

30. Galelli A, Truffa-Bachi P (1993) Urtica dioica agglutinin. A superantigenic lectin from stinging nettle rhizome. J Immunol 151(4):1821-1831

31. Gangadhar BH, Sajeesh K, Venkatesh J, Baskar V, Abhinandan K, Yu JW et al (2016) Enhanced tolerance of transgenic potato plants over-expressing non-specific lipid transfer protein-1 (StnsLTP1) against multiple abiotic stresses. Front Plant Sci 7:1228

32. Garcia-Olmedo F, Molina A, Alamillo JM, Rodriguez-Palenzuela P (1998) Plant defense peptides. Biopolymers 47(6):479-491. https://doi.org/10. 1002/(SICI) 1097-0282(1998)47:6\%3c479::AID-BIP6\%3e3.0.CO;2-K

33. Gidrol X, Chrestin H, Tan H-L, Kush A (1994) Hevein, a lectin-like protein from Hevea brasiliensis (rubber tree) is involved in the coagulation of latex. J Biol Chem 269(12):9278-9283

34. Giordani T, Buti M, Natali L, Pugliesi C, Cattonaro F, Morgante M, Cavallini A (2011) An analysis of sequence variability in eight genes putatively involved in drought response in sunflower (Helianthus annuus L.). Theor Appl Genet 122(6):1039-1049. https://doi.org/10.1007/ s00122-010-1509-0

35. Gomez-Casado C, Diaz-Perales A (2016) Allergen-associated immunomodulators: modifying allergy outcome. Arch Immunol Ther Exp (Warsz) 64(5):339-347. https://doi.org/10.1007/s00005-016-0401-2

36. Guzman-Rodriguez JJ, Ochoa-Zarzosa A, Lopez-Gomez R, Lopez-Meza JE (2015) Plant antimicrobial peptides as potential anticancer agents. Biomed Res Int 2015:735087. https://doi.org/10.1155/2015/735087

37. Han GW, Lee JY, Song HK, Chang C, Min K, Moon J et al (2001) Structural basis of non-specific lipid binding in maize lipid-transfer protein complexes revealed by high-resolution X-ray crystallography. J Mol Biol 308(2):263-278. https://doi.org/10.1006/jmbi.2001.4559

38. Harata K, Muraki M (2000) Crystal structures of Urtica dioica agglutinin and its complex with tri-N-acetylchitotriose. J Mol Biol 297(3):673-681

39. Huang R-H, Xiang Y, Liu X-Z, Zhang Y, Hu Z, Wang D-C (2002) Two novel antifungal peptides distinct with a five-disulfide motif from the bark of Eucommia ulmoides Oliv. FEBS Lett 521(1-3):87-90

40. Huang R-H, Xiang Y, Tu G-Z, Zhang Y, Wang D-C (2004) Solution structure of Eucommia antifungal peptide: a novel structural model distinct with a five-disulfide motif. Biochemistry 43(20):6005-6012

41. Huang X, Xie W-J, Gong Z-Z (2000) Characteristics and antifungal activity of a chitin binding protein from Ginkgo biloba. FEBS Lett 478(1-2):123-126

42. Iseli B, Boller T, Neuhaus J-M (1993) The N-terminal cysteine-rich domain of tobacco class I chitinase is essential for chitin binding but not for catalytic or antifungal activity. Plant Physiol 103(1):221-226

43. James DJ, Passey AJ, Barbara DJ, Bevan M (1989) Genetic transformation of apple (Malus pumila Mill) using a disarmed Ti-binary vector. Plant Cell $\operatorname{Rep} 7(8): 658-661$

44. Ji H, Gheysen G, Ullah C, Verbeek R, Shang C, De Vleesschauwer D et al (2015) The role of thionins in rice defence against root pathogens. Mol Plant Pathol 16(8):870-881. https://doi.org/10.1111/mpp.12246

45. Jimenez-Barbero J, Cañada FJ, Asensio JL, Aboitiz N, Vidal P, Canales A et al (2006) Hevein domains: an attractive model to study carbohydrate-protein interactions at atomic resolution. Adv Carbohydr Chem Biochem 60:303-354

46. Joly V, Matton DP (2015) KAPPA, a simple algorithm for discovery and clustering of proteins defined by a key amino acid pattern: a case study of the cysteine-rich proteins. Bioinformatics 31(11):1716-1723. https:// doi.org/10.1093/bioinformatics/btv047

47. Jose-Estanyol M, Gomis-Ruth FX, Puigdomenech P (2004) The eightcysteine motif, a versatile structure in plant proteins. Plant Physiol Biochem 42(5):355-365. https://doi.org/10.1016/j.plaphy.2004.03.009

48. Jung HW, Kim W, Hwang BK (2003) Three pathogen-inducible genes encoding lipid transfer protein from pepper are differentially activated by pathogens, abiotic, and environmental stresses. Plant Cell Environ 26(6):915-928. https://doi.org/10.1046/j.1365-3040.2003.01024.x

49. Kader JC (1975) Proteins and the intracellular exchange of lipids. I. Stimulation of phospholipid exchange between mitochondria and microsomal fractions by proteins isolated from potato tuber. Biochim Biophys Acta 380(1):31-44

50. Kader JC, Julienne M, Vergnolle C (1984) Purification and characterization of a spinach-leaf protein capable of transferring phospholipids from 
liposomes to mitochondria or chloroplasts. Eur J Biochem 139(2):411416. https://doi.org/10.1111/j.1432-1033.1984.tb08020.x

51. Kalla R, Shimamoto K, Potter R, Nielsen PS, Linnestad C, Olsen OA (1994) The promoter of the barley aleurone-specific gene encoding a putative $7 \mathrm{kDa}$ lipid transfer protein confers aleurone cell-specific expression in transgenic rice. Plant J 6(6):849-860. https://doi.org/10.1046/j.1365-313x. 1994.6060849.x

52. Kim H, Lee SB, Kim HJ, Min MK, Hwang I, Suh MC (2012) Characterization of -anchored lipid transfer protein 2 (LTPG2) and overlapping function between LTPG/LTPG1 and LTPG2 in cuticular wax export or accumulation in Arabidopsis thaliana. Plant Cell Physiol 53(8):1391-1403. https://doi. org/10.1093/pcp/pcs083

53. Kini SG, Nguyen PQ, Weissbach S, Mallagaray A, Shin J, Yoon HS, Tam JP (2015) Studies on the chitin binding property of novel cysteine-rich peptides from Alternanthera sessilis. Biochemistry 54(43):6639-6649

54. Kini SG, Wong KH, Tan WL, Xiao T, Tam JP (2017) Morintides: cargo-free chitin-binding peptides from Moringa oleifera. BMC Plant Biol 17(1):68

55. Koo JC, Chun HJ, Park HC, Kim MC, Koo YD, Koo SC et al (2002) Overexpression of a seed specific hevein-like antimicrobial peptide from Pharbitis nil enhances resistance to a fungal pathogen in transgenic tobacco plants. Plant Mol Biol 50(3):441-452

56. Koo JC, Lee SY, Chun HJ, Cheong YH, Choi JS, Kawabata S et al (1998) Two hevein homologs isolated from the seed of Pharbitis nil L. exhibit potent antifungal activity. Protein Struct Mol Enzymol 1382(1):80-90

57. Kristensen AK, Brunstedt J, Nielsen KK, Roepstorff P, Mikkelsen JD (2000) Characterization of a new antifungal non-specific lipid transfer protein (nsLTP) from sugar beet leaves. Plant Sci 155(1):31-40. https://doi.org/10. 1016/s0168-9452(00)00190-4

58. Lagier F, Vervloet D, Lhermet I, Poyen D, Charpin D (1992) Prevalence of latex allergy in operating room nurses. J Allergy Clin Immunol 90(3):319-322

59. Lee H, Broekaert W, Raikhel N, Lee H (1991) Co-and post-translational processing of the hevein preproprotein of latex of the rubber tree (Hevea brasiliensis). J Biol Chem 266(24):15944-15948

60. Lee H, Raikhel N (1995) Prohevein is poorly processed but shows enhanced resistance to a chitin-binding fungus in transgenic tomato plants. Br J Medical Biol Res 28(7):743

61. Lee OS, Lee B, Park N, Koo JC, Kim YH, Karigar C et al (2003) Pn-AMPs, the hevein-like proteins from Pharbitis nil confers disease resistance against phytopathogenic fungi in tomato Lycopersicum esculentum. Phytochemistry 62(7):1073-1079

62. Lee SB, Go YS, Bae HJ, Park JH, Cho SH, Cho HJ et al (2009) Disruption of glycosylphosphatidylinositol-anchored lipid transfer protein gene altered cuticular lipid composition, increased plastoglobules, and enhanced susceptibility to infection by the fungal pathogen Alternaria brassicicola. Plant Physiol 150(1):42-54. https://doi.org/10.1104/pp.109.137745

63. Li S-S, Claeson P (2003) Cys/Gly-rich proteins with a putative single chitin-binding domain from oat (Avena sativa) seeds. Phytochemistry 63(3):249-255

64. Liapkova N, Loskutova N, Măsurian A, Mazin V, Korableva N, Platonova Tet al (2001) Isolation of genetically modified potato plant containing the gene of defensive peptide from Am. Prikl Biokhim Mikrobiol 37(3):349-354

65. Lin P, Xia L, Ng T (2007) First isolation of an antifungal lipid transfer peptide from seeds of a Brassica species. Peptides 28(8):1514-1519

66. Lipkin A, Anisimova V, Nikonorova A, Babakov A, Krause E, Bienert M et al (2005) An antimicrobial peptide Ar-AMP from amaranth (Amaranthus retroflexus $L$.) seeds. Phytochemistry 66(20):2426-2431

67. Liu F, Zhang X, Lu C, Zeng X, Li Y, Fu D, Wu G (2015) Non-specific lipid transfer proteins in plants: presenting new advances and an integrated functional analysis. J Exp Bot 66(19):5663-5681. https://doi.org/10.1093/ jxb/erv313

68. Maldonado AM, Doerner P, Dixon RA, Lamb CJ, Cameron RK (2002) A putative lipid transfer protein involved in systemic resistance signalling in Arabidopsis. Nature 419(6905):399-403. https://doi.org/10.1038/natur e00962

69. Mareška V, Tvaroška I, Králová B, Spiwok V (2015) Molecular simulations of hevein/(GlcNAc) 3 complex with weakened $\mathrm{OH} / \mathrm{O}$ and $\mathrm{CH} / \pi$ hydrogen bonds: Implications for their role in complex stabilization. Carbohyd Res 408:1-7
70. Martins JC, Maes D, Loris R, Pepermans HA, Wyns L, Willem R, Verheyden P (1996) 1 H NMR study of the solution structure of Ac-AMP2, a sugar binding antimicrobial protein isolated from Amaranthus caudatus. J Mol Biol 258(2):322-333

71. Mohan S, Meiyalaghan S, Latimer JM, Gatehouse ML, Monaghan KS, Vanga BR et al (2014) GSL2 over-expression confers resistance to Pectobacterium atrosepticum in potato. Theor Appl Genet 127(3):677-689. https://doi.org/10.1007/s00122-013-2250-2

72. Molina A, Segura A, Garcia-Olmedo F (1993) Lipid transfer proteins (nsLTPS) from barley and maize leaves are potent inhibitors of bacterial and fungal plant pathogens. FEBS Lett 316(2):119-122. https://doi.org/10. 1016/0014-5793(93)81198-9

73. Nielsen KK, Nielsen JE, Madrid SM, Mikkelsen JD (1997) Characterization of a new antifungal chitin-binding peptide from sugar beet leaves. Plant Physiol 113(1):83-91

74. Nieuwland J, Feron R, Huisman BA, Fasolino A, Hilbers CW, Derksen J, Mariani C (2005) Lipid transfer proteins enhance cell wall extension in tobacco. Plant Cell 17(7):2009-2019

75. Nordstrom R, Malmsten M (2017) Delivery systems for antimicrobial peptides. Adv Colloid Interface Sci 242:17-34. https://doi.org/10.1016/j. cis.2017.01.005

76. Odintsova TI, Vassilevski AA, Slavokhotova AA, Musolyamov AK, Finkina El, Khadeeva NV et al (2009) A novel antifungal hevein-type peptide from Triticum kiharae seeds with a unique 10-cysteine motif. FEBS J 276(15):4266-4275

77. Pan Y, Li J, Jiao L, Li C, Zhu D, Yu J (2016) A non-specific Setaria italica lipid transfer protein gene plays a critical role under abiotic stress. Front Plant Sci 7:1752

78. Pasquato N, Berni R, Folli C, Folloni S, Cianci M, Pantano S et al (2006) Crystal structure of peach Pru p3, the prototypic member of the family of plant non-specific lipid transfer protein pan-allergens. J Mol Biol 356(3):684-694. https://doi.org/10.1016/j.jmb.2005.11.063

79. Petersen A, Kleine-Tebbe J, Scheurer S (2017). Stable plant food allergens I: lipid-transfer proteins. In: Molecular Allergy Diagnostics. Springer, pp 57-75

80. Regente MC, De La Canal L (2000) Purification, characterization and antifungal properties of a lipid-transfer protein from sunflower (Helianthus annuus) seeds. Physiol Plant 110(2):158-163

81. Rivillas-Acevedo LA, Soriano-García M (2007) Isolation and biochemical characterization of an antifungal peptide from Amaranthus hypochondriacus seeds. J Agric Food Chem 55(25):10156-10161

82. Shukurov RR, Voblikova VD, Nikonorova AK, Komakhin RA, Komakhina VV, Egorov TA et al (2012) Transformation of tobacco and Arabidopsis plants with Stellaria media genes encoding novel hevein-like peptides increases their resistance to fungal pathogens. Transgenic Res 21(2):313-325

83. Sohal AK, Pallas JA, Jenkins GI (1999) The promoter of a Brassica napus lipid transfer protein gene is active in a range of tissues and stimulated by light and viral infection in transgenic Arabidopsis. Plant Mol Biol 41(1):75-87. https://doi.org/10.1023/a:1006232700835

84. Souza AA, Costa AS, Campos DCO, Batista AHM, Sales GWP, Nogueira NAP et al (2018) Lipid transfer protein isolated from noni seeds displays antibacterial activity in vitro and improves survival in lethal sepsis induced by CLP in mice. Biochimie 149:9-17. https://doi.org/10.1016/j.biochi.2018.03. 011

85. Sterk P, Booij H, Schellekens GA, Van Kammen A, De Vries SC (1991) Cellspecific expression of the carrot EP2 lipid transfer protein gene. Plant Cell 3(9):907-921

86. Sy D, Le Gravier Y, Goodfellow J, Vovelle F (2003) Protein stability and plasticity of the hydrophobic cavity in wheat ns-LTP. J Biomol Struct Dyn 21(1):15-29. https://doi.org/10.1080/07391102.2003.10506902

87. Terras FR, Goderis IJ, Van Leuven F, Vanderleyden J, Cammue BP, Broekaert WF (1992) In vitro antifungal activity of a radish (Raphanus sativus L.) seed protein homologous to nonspecific lipid transfer proteins. Plant Physiol 100(2):1055-1058. https://doi.org/10.1104/pp.100.2.1055

88. Thomas WR (2014) Allergen ligands in the initiation of allergic sensitization. Curr Allergy Asthma Rep 14(5):432

89. Tian N, Liu F, Wang P, Yan X, Gao H, Zeng X, Wu G (2018) Overexpression of BraLTP2, a lipid transfer protein of Brassica napus, results in increased trichome density and altered concentration of secondary metabolites. Int J Mol Sci 19(6):1733 
90. Tordesillas L, Gómez-Casado C, Garrido-Arandia M, Murua-García A, Palacin A, Varela J et al (2013) Transport of Pru p3 across gastrointestinal epithelium - an essential step towards the induction of food allergy? Clin Exp Allergy 43(12):1374-1383

91. Van den Bergh KP, Proost P, Van Damme J, Coosemans J, Van Damme EJ, Peumans WJ (2002) Five disulfide bridges stabilize a hevein-type antimicrobial peptide from the bark of spindle tree (Euonymus europaeus L.). FEBS Lett 530(1-3):181-185

92. Volpicella M, Leoni C, Fanizza I, Rinalducci S, Placido A, Ceci LR (2015) Expression and characterization of a new isoform of the $9 \mathrm{kDa}$ allergenic lipid transfer protein from tomato (variety San Marzano). Plant Physiol Biochem 96:64-71

93. Wong KH, Tan WL, Serra A, Xiao T, Sze SK, Yang D, Tam JP (2016) Ginkgotides: proline-rich hevein-like peptides from gymnosperm Ginkgo biloba. Front Plant Sci 7:1639
94. Xiang Y, Huang R-H, Liu X-Z, Zhang Y, Wang D-C (2004) Crystal structure of a novel antifungal protein distinct with five disulfide bridges from Eucommia ulmoides Oliver at an atomic resolution. J Struct Biol 148(1):86-97

95. Zasloff M (2002) Antimicrobial peptides of multicellular organisms. Nature 415(6870):389-395. https://doi.org/10.1038/415389a

96. Zhang D, Liang W, Yin C, Zong J, Gu F, Zhang D (2010) OsC6, encoding a lipid transfer protein, is required for postmeiotic anther development in rice. Plant Physiol 154(1):149-162. https://doi.org/10.1104/pp.110.158865

\section{Publisher's Note}

Springer Nature remains neutral with regard to jurisdictional claims in published maps and institutional affiliations.

\section{Submit your manuscript to a SpringerOpen ${ }^{\circ}$ journal and benefit from:}

- Convenient online submission

- Rigorous peer review

- Open access: articles freely available online

- High visibility within the field

- Retaining the copyright to your article

Submit your next manuscript at $\boldsymbol{\nabla}$ springeropen.com 